http://dx.doi.org/10.18232/alhe.961

Artículos

\title{
Invenciones institucionales: el sistema de patentes en las colonias españolas durante el siglo XIX
}

\section{Institutional Inventions: The Patent System in the Spanish Colonies during the 19th Century}

David Pretel $^{1, *}$ * 0000-0002-9095-6449

${ }^{1}$ El Colegio de México, Ciudad de México, México

*Correspondencia: dpretel@colmex.mx

Resumen. Este trabajo ofrece un estudio de los sistemas coloniales de patentes durante el siglo XIX. En primer lugar, se muestra la heterogeneidad en la regulación y práctica administrativa de las instituciones de patentes coloniales en los distintos imperios atlánticos, con especial atención al caso de América Latina. En segundo lugar, se estudia en detalle el funcionamiento y la evolución institucional del sistema de patentes colonial en Puerto Rico, Cuba y Filipinas. Se sostiene que entre 1820 y 1860 este sistema fue una institución imperfecta, de corte neomercantilista, controlada por las corporaciones coloniales y que servía de espacio colectivo de intercambio de información tecnológica. En tercer lugar, se muestra la reconfiguración del sistema de patentes en las colonias españolas durante las dos últimas décadas del siglo XIX, en un contexto de acuerdos multilaterales y creciente influencia estadunidense.

Palabras clave: patentes; colonialismo; neomercantilismo; instituciones; tecnología.

Abstract. This article studies the colonial patent systems during the $19^{\text {th }}$ century. First, it shows the heterogeneity in the regulation and administrative practice of the colonial patent institutions in the various Atlantic empires, with particular attention to the case of Latin America. Second, it examines in detail the functioning

CÓMO CITAR: Pretel, D. (2019). Invenciones institucionales: el sistema de patentes en las colonias españolas durante el siglo XIX. America Latina en la Historia Económica, 26(2), e961. DOI: 10.18232/alhe.961 
and institutional evolution of the colonial patent system in Puerto Rico, Cuba and the Philippines. Between 1820 and 1860, this system was an imperfect institution, of a neo-mercantilist nature, controlled by the colonial corporations and that served as a collective space for the exchange of technological information. Third, it shows the reconfiguration of the patent system in the Spanish colonies during the last two decades of the $19^{\text {th }}$ century, in a context of multilateral agreements and growing US influence.

Key words: patents; colonialism; neo-mercantilism; institutions; technology.

JEL: N26; 031; 034; P48.

Recibido: 23 de febrero de 2018.

Aceptado: 17 de abril de 2018.

Publicado: 29 de enero de 2019.

Organismo colaborador: Ministerio de Economía, Industria y Competitividad, España, Proyecto HAR2016-75010-R.

Agradezco las observaciones de Patricio Sáiz, Nadia Fernández de Pinedo, María Cecilia Zuleta y Rodrigo Vega, así como de los dos evaluadores anónimos, a versiones anteriores de este texto.

\section{DIVERSIDAD INSTITUCIONAL Y SISTEMAS COLONIALES DE PATENTES}

Las instituciones de patentes son invenciones en sí mismas, que proliferaron en las sociedades atlánticas a lo largo del siglo XIX. Los sistemas de patentes decimonónicos fueron instituciones cimentadas sobre un ethos jurídico-institucional común, si bien en la práctica tenían reglas y estándares diferentes (Inkster, 2012; May y Sell, 2006). La profunda diversidad internacional de las instituciones de fomento de la innovación durante el siglo XIx no se explica únicamente por las diferencias en los principios legales nacionales o las culturas de la invención y la propiedad. La heterogénea evolución institucional de los sistemas de propiedad industria 1 durante el siglo XIX respondió, en gran medida, a las necesidades de cada sociedad y a los determinantes de la economía internacional. Los derechos de patentes fueron redefinidos por las distintas sociedades, haciéndolos operativos y confiriéndoles significados específicos. Los sistemas de patentes fueron, además de una institución de defensa de los derechos de los inventores, un instrumento de política económica para el estímulo de las economías nacionales o locales ${ }^{2}$

Numerosos economistas e historiadores de la economía han mostrado que una de las formas más aproximadas de determinar las capacidades tecnológicas nacionales desde el siglo xix es a partir del análisis comparativo internacional de la cantidad de patentes de invención registradas en los distintos países, si bien este indicador no está exento de problemas metodológicos (Edgerton, 1999; Inkster, 2003) $]^{3}$ Desde esta perspectiva, los sistemas de protección de la propiedad industrial de los inventores, además de su influencia como institución social, son una fuente histórica de

${ }^{1}$ La legislación de propiedad industrial hace referencia a la regulación de patentes de invención, marcas de fábrica y modelos industriales.

${ }^{2}$ Las instituciones que estimulan el desarrollo económico han sido interpretadas y organizadas de manera distinta en diferentes contextos nacionales. Véanse Gerschenkron (1962), Trentmann y Daunton (2004), North (1990) y Ostrom (2015).

${ }^{3}$ Las estadísticas de patentes presentan ciertos inconvenientes y sesgos que son más pronunciados, si cabe, en aquellas sociedades que no han sustentado su desarrollo económico en la actividad inventiva, sino en la imitación y transferencia de tecnología extranjera. No todos los inventos ideados en el siglo xix fueron patentados, y, entre los que sí lo fueron, muchos no llegaron a ser aplicados industrialmente. Las patentes aplicadas a la industria son, por lo tanto, sólo una parte de la innovación tecnológica. Además, no todos los países tenían sistemas de patentes equiparables y otros se demoraron en disponer de una primera ley, por lo que las comparativas son problemáticas. 
primer orden para clasificar a los países en función de su capacidad tecnológica y dependencia del exterior, lo que permite realizar comparaciones recíprocas que de otra manera serían difíciles. Las patentes constituirían un indicador fiable, aunque imperfecto, de la evolución y el desarrollo económicos (Streb, 2016; Griliches, 1990). Otros autores consideran, por el contrario, que durante el siglo xix los derechos de patentes fueron una restricción legal para la difusión internacional del conocimiento tecnológico, debido a que las leyes de propiedad y los acuerdos bilaterales e internacionales no eran respetados, y a que incluso las legislaciones de patentes concedían derechos de propiedad sobre la invención a importadores de tecnología (Chang, 2001, 2003).

La agregación de datos de patentes y su estudio cuantitativo en el largo plazo, habitual en la literatura especializada, oculta la heterogeneidad de los distintos sistemas nacionales de patentes. Durante el siglo XIX existían profundas diferencias en la legislación y una diversidad en las culturas de regulación de la propiedad industrial (Arapostathis y Gooday, 2013; Inkster, 2009; Pretel, 2017). Las diferencias se encuentran en los ordenamientos legales, pero sobre todo en la práctica burocrática y la organización institucional. El ejemplo más claro son las marcadas diferencias entre sistemas de registro y sistemas con examen de novedad, pero también había disparidad en cuestiones como la composición de los órganos de concesión, el costo de solicitud, el estatus de los inventores extranjeros, la redacción de especificaciones, la presencia de intermediarios, la efectiva explotación de la patente, la cesión de derechos a terceros, la duración del monopolio, la regulación de modelos de utilidad y las materias patentables (Thompson, 1882).

De entre los múltiples regímenes de propiedad industrial decimonónicos, la pervivencia de sistemas de patentes coloniales es un excelente ejemplo de esta diversidad institucional internacional. La coexistencia de sistemas de propiedad industrial coloniales en distintos imperios atlánticos es una cuestión apenas abordada por la historiografía. Los estudios disponibles han tendido a un análisis superficial de la regulación colonial, a menudo centrado en estudios cuantitativos, sin problematizar cuestiones como la práctica administrativa, la infraestructura social, la cultura tecnológica y los actores sociales participantes en la regulación y funcionamiento institucional. El análisis de la institucionalización del derecho de patentes en sociedades coloniales puede proporcionar una radiografía más precisa de la divergente evolución de los distintos sistemas de propiedad intelectual a nivel internacional durante el siglo xIx.

Desde época temprana encontramos ejemplos de concesiones de patentes de invención en colonias francesas, inglesas y españolas. Desde comienzos del siglo XviI las colonias inglesas en América del norte empezaron a conceder monopolios de patente de forma discrecional (Bently, 2011; Bracha, 2016). Las entonces colonias de Massachusetts, Connecticut, Rhode Island, Nueva York, Virginia, Carolina del Sur y Plymouth concedieron patentes de invención, sobre todo a invenciones agrícolas, como recoge el catálogo de patentes elaborado por el prestigioso abogado londinense Bennet Woodcroft (1969). Entre 1839 y 1846 también se concedieron patentes en Texas (Muir, 1946), incluso hubo una Oficina de Patentes Confederada que otorgó 274 patentes durante los cuatro años (1861-1865) en que estuvo en funcionamiento (Knight, 2011).

En el caso del imperio británico, hubo sistemas coloniales de patentes en India, Canadá, Australia y distintas islas del Atlántico y Pacífico. Siguiendo los principios de derecho consuetudinario (o derecho común) de tradición anglosajona, estos sistemas permanecieron sin regulación legislativa hasta al menos la ley de propiedad intelectual inglesa de 1852 (Bently, 2011; Nard, 2010). A partir de ese momento las patentes concedidas en Inglaterra debían ser respetadas en las colonias británicas, limitando de esta manera la libre explotación de técnicas agrícolas patentadas en suelo inglés. Sin embargo, la ley de 1852 excluía explícitamente a las colonias de su ámbito de regula- 
ción. Esta relativa estandarización de la legislación suscitó el rechazo de las autoridades coloniales y hacendados agrícolas en el Caribe que las consideraban de poca utilidad o preferían las regulaciones locales más laxas en la utilización de técnicas extranjeras. Así, las colonias británicas sin legislación de patentes o con sistemas imperfectos de concesión mantenían una ventaja comparativa en la utilización de tecnologías extranjeras sin restricción alguna. En el caso de la India, por el contrario, la legislación de patentes de 1856 discriminaba a los inventores indios en relación con los británicos, excluyéndolos de esta manera del sistema (Sagar, 2007).

En 1864 pervivían 17 legislaciones coloniales en el imperio británico, de entre ellas, el ejemplo australiano es especialmente interesante (Bently, 2011; Todd, 1995). Antes del establecimiento de la Oficina de Patentes de la Commonwealth en 1904, cada colonia australiana gestionó su sistema independiente de patentes sin adoptar un sistema uniforme. Seis sistemas formales fueron establecidos entre 1852 y 1876, sin reconocimiento de derechos de propiedad entre ellos (Queensland, Western Australia, New South Wales, Victoria, Tasmania y South Australia); en principio, estos sistemas respetaban el estatus de la legislación británica de 1852, y en la práctica cada sistema tenía distintos procedimientos de solicitud, costos de registro, criterios de patentabilidad, duración del monopolio y publicidad. La legislación de patentes era un instrumento de política tecnológica con el objetivo de establecer nuevas industrias. Otras posesiones británicas, como Hong Kong, no tendrán legislación de patentes durante el siglo XIX. A partir del decenio de 1870, las colonias británicas se mostrarán más receptivas a la asimilación de la legislación de patentes inglesa ante las oportunidades que podían abrir los acuerdos internacionales (Ricketson, 2015).

En el caso francés, algunas colonias caribeñas, como Martinica, Guadalupe, Reunión y Guyana, establecieron regímenes de patentes complementarios al sistema metropolitano de patentes desde mediados del siglo xviII. En estas colonias, los gobernadores generales concedían patentes provisionales, sobre todo vinculadas a la industria azucarera, con el objetivo de estimular las economías coloniales. Será entre 1844 y 1849 cuando se empezarán a regular en Francia la concesión de patentes en las colonias (Gálvez-Behar, 2016).

Con anterioridad al siglo xIX pueden localizarse varias concesiones de privilegios de invención en la América española. La extensión de estas prácticas es una cuestión insuficientemente explorada por la historiografía. Sí tenemos constancia de la concesión, desde época temprana, de privilegios de invención para mejoras en técnicas mineras y agrícolas (Escobar, 2004; Sánchez, 1980; Sánchez, 1997). Durante el primer tercio del siglo xix, las recién independizadas repúblicas latinoamericanas incorporan legislaciones de propiedad intelectual, como México (1832), Brasil (1830) y Chile (1840). Ya en la segunda mitad del siglo xIx, otros países de la región también establecerán regulaciones modernas de propiedad industrial como Uruguay (1853), Argentina (1864), Perú (1869) y Venezuela (1878) 4 En 1873, ocho países de América Latina tienen legislaciones nacionales de patentes, lo que contrasta con la situación en Asia y África, donde sólo hay un país con regulación en cada continente. Eso se explica, en gran medida, por el relativamente tardío proceso de descolonización en África y Asia. Así, para 1900 en América Latina quince naciones tenían legislación de patentes, por cuatro africanas y dos asiáticas (Patel, 1974).

\footnotetext{
${ }^{4}$ En el contenido de la legislación de patentes en estas repúblicas latinoamericanas había una diversidad importante; por ejemplo, en la ley de Ecuador de 1880 se señalaba que el Estado podía adquirir, por medio de compra, el secreto de cualquier invento útil para la industria y hacerlo público.
} 
En América Latina los promotores de estas regulaciones buscaban superar el legado colonial y establecer instituciones que, como los sistemas de patentes, promovieran la construcción liberal del Estado (Beatty, 2001). Los legisladores de estas nuevas repúblicas se propusieron trascender la herencia colonial que trataba los derechos de patentes como privilegios de prerrogativa real. Las elites latinoamericanas establecieron sistemas basados en el ideal utilitarista de progreso económico de la nación. Hay excepciones a esta tendencia, como Haití y República Dominicana, que no tuvieron leyes de patentes durante el siglo XIX, aunque sí se adhirieron a convenios internacionales sobre derechos de patentes en el último tercio de tal siglo. Varios países, como Chile, Perú, Argentina y Brasil, admitieron las patentes de introducción, también llamadas de importación, modalidad de protección reconocida en España y sus territorios de ultramar. El objetivo de esta legislación era favorecer la imitación de tecnologías extranjeras, independientemente de que el solicitante de la patente fuera o no el inventor original (Thompson, 1882).

\section{El sistema de patentes en Ciuba, Puerto Rico y Filipinas ${ }^{5}$}

Tras los procesos de independencia de la América española, entre 1809 y 1826, España conservará hasta 1898 las colonias de su segundo imperio: Cuba, Filipinas y Puerto Rico. Estas colonias, especialmente Cuba, pasarán a ser parte fundamental del mercado nacional de la España liberal tanto desde un punto de vista estrictamente económico como del imaginario político. Estas colonias experimentaron una intensa transformación económica durante el siglo xIx. Entre 1830 y 1860, la industria azucarera cubana y puertorriqueña asistieron a un proceso de modernización tecnológica, una transición hacia un modelo agroindustrial de gran escala, intensivo en maquinaria, con presencia de expertos cualificados, pero manteniendo el trabajo esclavo en la plantación (CabreraSalcedo, 2010; Curry-Machado, 2011; Ortega, 2014). Como muestran las balanzas comerciales y los registros de maquinistas de la isla de Cuba, España desempeñó un papel poco destacado en esta transformación tecnológica, ante la incapacidad de suministrar maquinaria avanzada y trabajadores técnicos cualificados a los ingenios azucareros. Esto contrasta con la situación en otras islas productoras de azúcar, como Java y Jamaica, donde las metrópolis fueron activas en el proceso de mecanización de las plantaciones de sus respectivas colonias (Pretel y Fernández de Pinedo, 2015). José Alcover, ingeniero industrial y agente de patentes, resumió de manera elocuente esta situación en 1884: "nuestras Antillas fueron elegidas por ciertos constructores extranjeros como mercado especial para colocar las que llaman máquinas de exportación” (Alcover, 1884) ${ }^{6}$

\footnotetext{
${ }^{5} \mathrm{El}$ contenido de esta sección se fundamenta en un estudio de la legislación sobre la propiedad industrial y la documentación original de patentes solicitadas en España durante el siglo xIX, información recogida en el Archivo de la Oficina Española de Patentes y Marcas (en adelante AHовPM) y en el Boletín Oficial de la Propiedad Industrial. Con el objetivo de estudiar el sistema de patentes colonial se ha consultado, también, la documentación del Archivo Nacional de Cuba (ANC); se han estudiado también distintas publicaciones y revistas de las elites coloniales, como las Memorias de la Sociedad Económica de La Habana y la Revista de Agricultura; finalmente, se han consultado los expedientes de convalidación en las colonias de patentes concedidas en la península entre 1888 y 1893, material disponible en el Archivo Histórico Nacional (AHN), sección Ultramar.

${ }^{6}$ La presencia de tecnología y maquinistas extranjeros también era frecuentemente resaltada por las revistas técnicas estadunidenses, como por ejemplo Scientific American. En el ANC -Correspondencia, Fondo Valle Iznaga- se encuentra documentación de varios contratos de maquinistas extranjeros empleados en las décadas de 1840 y 1850 por los ingenios Soledad, Niña y Santa Ana.
} 
A pesar de la riqueza de las economías coloniales y de la consideración de estos dominios como parte central de la nación, las elites criollas estuvieron en gran parte excluidas de las reformas políticas liberales llevadas a cabo en los decenios centrales del siglo xIx (Schmidt-Nowara, 2004). La metrópoli tampoco pareció tener especial interés en estimular la industria e innovación tecnológica en las colonias. Las elites criollas disfrutaron, desde finales del siglo xviII, de una relativa autonomía en la administración de las economías coloniales (Moreno, 1995). La legislación española decimonónica, por influencia francesa, era dual, con leyes especiales para los territorios de ultramar (Fradera, 2008). Así, en materia de propiedad industrial, hubo una legislación específica para las colonias (real cédula de 1833 y real decreto de 1880) distinta a la que se aplicaba en la península (leyes de 1820, 1826 y 1878). 7

Encontramos concesiones de privilegio de invención desde las colonias con anterioridad a la promulgación de la ley de 1833; por ejemplo, Fernando Arritola, mecánico residente en La Habana, presentó solicitud, remitida a las autoridades coloniales en 1819, de un privilegio exclusivo para fabricar un alambique de azúcar, y en 1820 protección por una mejora del mismo destilador 8 El expediente presentado por Arritola en 1819 carecía de dibujo o modelo, pero la Comisión de Agricultura, Industria y Artes de las Cortes Españolas en Madrid accedió en 1820 a su solicitud y señaló que dada la distancia de las posesiones de ultramar las solicitudes de privilegios de invención podían presentarse directamente ante las autoridades coloniales 9 Encontramos otros privilegios de invención para las colonias anteriores a la ley de 1833, tramitados por el Real Conservatorio de Artes de Madrid. Así, por ejemplo, en abril de 1824 les fue concedido a Lorenzo Calvo y Domingo Rojas ${ }^{10}$ prominentes hombres de negocios de Manila con importante influencia política (Fradera, 1999), un privilegio de introducción por doce años con el objeto de instalar en las islas Filipinas una ferrería completa a vapor de construcción inglesa destinada a fundir, laminar y refinar el hierro ${ }^{11}$ En diciembre de ese mismo año, el Real Conservatorio les concedió a estos mismos comerciantes otro privilegio de introducción por doce años para una máquina de hilado y torcido de construcción extranjera 12

La legislación colonial de 1833, aunque sustantivamente similar a la ley de 1826, introducía algunos matices. El más importante era que restringía explícitamente la concesión de privilegios de introducción, también llamados de importación, en mejoras relacionadas con adelantos en téc-

\footnotetext{
${ }^{7}$ Real cédula del 30 de julio de 1833 (BN, Sig. H. A. 17303). La real cédula de 1833 fue publicada en la España metropolitana hasta la circular del 31 de enero de 1849 (CLE, t. XLVI). El término legal en el caso español, tanto metropolitano como en las colonias, hasta 1878, es el de privilegio de invención. Podemos encontrar, en ocasiones, referencias contemporáneas al término de patente o patente de privilegio. En este artículo se utilizan indistintamente los términos privilegio y patente.

${ }^{8}$ Real Consulado, leg. 204, exps. 9007 y 9008, ANc. A Arritola se le concedió privilegio de invención antes de que se sancionara el proyecto de propiedad industrial de 1820. Ya en el preámbulo de exposición de esta ley se propuso que, dada la distancia de las posesiones de ultramar, se concedieran los privilegios a nivel local en el momento de la reclamación hasta que pudieran ser revisados por una comisión metropolitana.

${ }^{9}$ Diario de las actas y discusiones de las Cortes (1820 y 1821 , t. Iv, pp. 237-246).

${ }^{10}$ Josep María Fradera (1999, pp. 113, 250 y 277) nos indica que Domingo de Rojas era uno de los más prominentes comerciantes de Filipinas con intereses en el comercio de tabaco, las ferrerías y en el cultivo de azúcar, introduciendo maquinaria en estos ramos. Rojas tenía importantes posiciones en instituciones de gobierno de la colonia. Calvo fue un personaje fundamental en la economía filipina y promotor de la minería de hierro en las islas. Rojas y Domingo fueron socios en distintos emprendimientos.

${ }^{11}$ Privilegio núm. 17, АНОЕРм.

${ }^{12}$ Privilegio núm. 33, АнОЕРм.
} 
nicas agrícolas. 13 Además, de acuerdo con la ley de 1833, las concesiones de privilegios debían publicarse en los respectivos Diarios de Gobierno y en la Gaceta de Madrid. En las colonias no existían oficinas de patentes exclusivas para la administración, concesión y publicidad de las patentes de invención. Desde 1833 y, al menos, hasta el decenio de 1860, el órgano encargado de la tramitación y el registro de las patentes en Cuba fue un consejo regido por la Real Junta de Fomento y Agricultura, corporación fundada por la oligarquía habanera (Marrero, 1984). Los requisitos administrativos requeridos por este consejo eran arbitrarios y era frecuente la concesión de privilegios sin que el solicitante presentara especificaciones o memoria técnica. La decisión final de la concesión era prerrogativa de las elites criollas, principales interesadas en modernizar sus plantaciones. La novedad de la invención se equiparaba con la idea de conocimiento público en la isla.

La legislación de 1833 dejaba espacio para una práctica administrativa arbitraria en la concesión de monopolios de invención. Al menos hasta el decenio de 1860, cada solicitud de patente fue estudiada caso por caso por medio de un procedimiento ad-hoc; la principal variable que determinaba la concesión de monopolio temporal era el beneficio económico de la invención para las economías agrarias coloniales, por encima de la novedad del invento o los derechos del inventor. ${ }^{14}$ A diferencia de lo que ocurría en la España metropolitana, donde la institución de patentes funcionaba como un sistema de registro sin examen de novedad, en las colonias se practicaba un exhaustivo examen de utilidad económica de las invenciones coloniales ${ }^{15}$ por lo que en la práctica, la concesión de patentes en las colonias españolas funcionaba como un sistema de privilegios con un examen previo de la utilidad de la invención para las economías coloniales. Puede decirse que en la España metropolitana la barrera para patentar era el costo del registro y, en ningún caso, el examen de la patente, pues, al igual que el sistema inglés, el español era un sistema de registro sin examen técnico previo. En cambio, en las colonias la barrera era no sólo el costo de solicitud, como consecuencia de las tasas adicionales de registro y la necesidad de utilizar intermediarios internacionales, sino sobre todo el examen practicado por las corporaciones locales. Parece, no obstante, que ambos sistemas, el metropolitano y el colonial, contaron con limitados recursos para asegurar el cumplimiento sustantivo de la reglamentación, siendo el objetivo principal de la protección de patentes la transferencia de tecnología extranjera (Pella y Forgás, 1892; Pretel, 2017; Sáiz, 2006) 16

\footnotetext{
${ }^{13}$ Real cédula del 30 de julio de 1833 por la que se extiende el real decreto del 17 de marzo de 1826 sobre invenciones e introducciones a los dominios de ultramar.

${ }^{14}$ Documentación de privilegios y patentes de invención en colecciones del ANc: Gobierno General, Gobierno Superior Civil, Real Consulado, Junta de Fomento e Intendencia de Hacienda.

${ }^{15}$ No hay sistemas de patentes decimonónicos que sigan de manera estricta la doctrina de derecho natural de los individuos a la propiedad del invento, que en todo caso sería perpetuo y universal. En realidad, todos los sistemas seguían, en mayor o menor medida, un principio de utilidad y de contrato entre la sociedad y los inventores. El sistema de patentes español tenía implícito un requerimiento de utilidad por medio de la certificación de puesta en práctica de la invención. Para un ejemplo temprano de argumentación en favor de un sistema de patentes basado en el derecho natural del inventor véase Privilegios de invención e introducción (Memorias de la Sociedad Patriótica, 1836, t. ii, pp. 89-99).

${ }^{16}$ En relación con el funcionamiento del sistema español de patentes, las palabras del abogado José Pella y Forgás (1892, p. 43) son elocuentes: "la vida de la propiedad industrial mostrose perezosa y escasa como lo corrobora el corto número de litigios. España, por otra parte, por lo menos la España moderna, sólo hasta muy reciente época, no ha poseído industria. Por ello la jurisprudencia, en materia de patentes escasea, y las Reales órdenes y otras disposiciones dictadas durante ese largo periodo se reducen a resolver puntos elementales".
} 
Para el dictamen final sobre la concesión de privilegios de invención en Cuba, la Junta de Fomento recababa informes de la Real Sociedad Económica, del Ayuntamiento de La Habana y de expertos técnicos independientes con conocimiento especializado, como el también inventor Mariano Vieta, doctor en farmacia, o el químico José Luis Casaseca ${ }^{17}$ El voto de las elites coloniales en esta materia era, en palabras de los propios miembros de la junta, "más estricta que indulgente para los [privilegios] de introducción y muy cauta en los de mejora" 18 Frecuentemente, con el objeto de preparar estos informes, se establecían comisiones para realizar ensayos de los nuevos procedimientos en las plantaciones ${ }^{19}$ Estos exámenes se vieron facilitados por la proximidad social entre los solicitantes y los encargados de la concesión. El abogado y secretario de la Real Sociedad Económica, Rafael Matamoros y Téllez, concluía en 1843, en relación con estos dictámenes, que "antes de expedir cédulas de privilegio por los inventos e introducción de máquinas y mejoras destinadas al fomento de la agricultura, el Gobierno ha consultado la opinión del Cuerpo; y podemos asegurar sin temor a engaños, que en nuestros informes han brillado los mejores principios de la ciencia económica, y los más puros de acertar para el bien del país" ${ }^{20}$ Esto no fue siempre así, la propia Sociedad Económica había denunciado en 1836 que estos informes eran en ocasiones errados y arbitrarios 21

Los extensos informes comisionados por la Junta de Fomento de Cuba para resolver sus dictámenes muestran que la cultura tecnológica en la plantación azucarera estaba identificada con la innovación incremental y la experimentación práctica. La cultura tecnológica en la plantación cubana, en los decenios centrales del siglo XIX, se caracterizaba por un esfuerzo por adaptar la tecnología extranjera a las particulares condiciones tropicales; era una práctica agroindustrial basada en el conocimiento tácito de las necesidades técnicas de la plantación que contrastaba con la cultura tecnológica más formal que podía encontrase en enclaves de la España metropolitana, como por ejemplo en las escuelas de ingeniería industrial (Curry-Machado, 2011; Pretel y Fernández de Pinedo, 2015; Rood, 2017). Con el objetivo de fomentar esta cultura tecnológica práctica la Sociedad Económica estableció en 1846 una escuela de maquinaria. Esta escuela se estableció en el mismo edificio que albergaba la Sociedad Económica con el propósito declarado de reducir la dependencia de maquinistas extranjeros empleados en plantaciones de azúcar, ferrocarriles y buques a vapor 22

Es importante subrayar el papel de otros incentivos públicos a la innovación. Las corporaciones controladas por las elites criollas cubanas utilizaron, en el periodo de 1830 a 1860, un conjunto de instrumentos alternativos de estímulo (premios monetarios, subsidios, medallas, exhibiciones, ensayos públicos y traducciones de manuales) que competía directamente con las patentes y que al parecer proporcionó mayores incentivos a la innovación. Estas iniciativas de promoción pública fueron solicitadas en ocasiones en la forma de privilegios de invención, cuando en realidad no cabían en los contornos legales de este tipo de protección.

\footnotetext{
${ }^{17}$ Por ejemplo, el 18 de febrero de 1850, Casaseca escribió un informe recomendando que se desestimara la solicitud de los hacendados Joaquín y don Pablo Arrieta de protección por un procedimiento para la depuración y clarificación del guarapo o cualquier otro líquido sacarino. Gobierno Superior Civil, leg. 1478. exp. 58495, ANc.

${ }^{18}$ Memorias de la Sociedad Patriótica (1839, t. Ix, p. 167).

${ }^{19}$ Véase, por ejemplo, el expediente promovido por Mariano Vieta. Junta de Fomento, leg. 95, exp. 4007, ANc.

${ }^{20}$ Memorias de la Sociedad Económica (1843, t. XVII, pp. 179-180).

${ }^{21}$ Memorias de la Sociedad Patriótica (1836, t. II, pp. 89-99).

${ }^{22}$ Memorias de la Real Sociedad Económica (1846, t. I, pp. 15-20).
} 
Las elites hacendadas implantaron simultáneamente una estrategia de difusión de la información tecnológica registrada y de datos estadísticos relacionados con los inventos. Esta información se transmitía a las clases agroindustriales a través de órganos oficiales, publicaciones corporativas, informes públicos y tratados monográficos ${ }^{23}$ Esta iniciativa de transmisión de información tecnológica al dominio público estaba sustentada en una concepción colectiva de la innovación, en la que los hacendados compartían libremente los avances agroindustriales surgidos de la experimentación práctica en la plantación, verdadero espacio de producción de conocimiento. La tecnología y otros conocimientos agroindustriales eran considerados un bien público no exclusivo. En este contexto, el sistema de patentes colonial era concebido como un espacio de intercambio de información, antes que una institución para la reclamación de derechos de propiedad del inventor. La competencia estaba en el mercado internacional, por el abaratamiento de los precios del azúcar y el auge de nuevos productores. La competencia entre los hacendados cubanos era amistosa, en palabras de Franklin Knight (1977), y centrada en el estatus social.

Entre los instrumentos de esta política corporativa de estímulo tecnológico encontramos las comisiones organizadas por la Junta de Fomento para inspeccionar las nuevas tecnologías introducidas en distintos ingenios de la isla, que mostraban la colocación, el funcionamiento y los resultados de las zafras. Asimismo, fueron frecuentes las expediciones científicas e industriales subvencionadas por la Junta de Fomento, iniciativa recogida en el articulado de creación de dicha corporación. Hacendados, funcionarios gubernamentales y científicos cubanos fueron enviados a Estados Unidos, Europa y otras islas del Caribe en busca de maquinaria y expertos extranjeros. Las nuevas técnicas descritas en los informes de estas comisiones no podían ser materia de privilegio, sino después de tres años desde su conocimiento en Cuba, y sólo si se daba la circunstancia de que no habían sido puestas en práctica en la isla.

Buen ejemplo es el viaje, en 1848, de José María de la Torre, catedrático de geografía de la Universidad de La Habana y socio de la Real Sociedad Económica, comisionado por la junta para visitar durante varios meses la Confederación Americana del Norte, incluidas las plantaciones azucareras de Luisiana y el museo de patentes de Washington ${ }^{24}$ Las notas de este comisionado fueron publicadas por la Sociedad Económica y en varios periódicos de Cuba, donde se incluyeron referencias a los principales tratados de cultivo y ganadería estadunidenses de la época, así como a estadísticas oficiales y modelos de máquinas e inventos. De la Torre remitió también a la junta semillas escogidas de distintas clases, incluidas las de algodón y trigo, así como pequeños instrumentos y maquinaria; además, dio a conocer en Cuba el tren de evaporación de Norbert Rillieux, que contaba con patentes de Estados Unidos y Francia. Otros ejemplos de viajes industriales costeados por la Real Junta para examinar progresos tecnológicos extranjeros incluyen la estancia de un año en Europa del prestigioso químico José Luis Casaseca, en 1842; la expedición de cinco meses de los hacendados Ramón Arozarena y Pedro Banduy a Jamaica, en 1828; o la visita de Alejandro de Olivar a Inglaterra y Francia, en 183025

\footnotetext{
${ }^{23}$ Entre ellas destacan las memorias y actas publicadas, bajo distintos nombres, por la Sociedad Económica. También destaca la información aparecida en la Gaceta de La Habana y, ya en el último tercio del siglo xix, La Revista de Agricultura del círculo de hacendados.

${ }^{24}$ Junta de Fomento, leg. 95, exp. 4021, Anc, y Anales de las Reales Junta de Fomento y Sociedad Económica (1849), pp. 293-302.

${ }^{25}$ Real Consulado y Junta de Fomento, leg. 95, exp. 3996, ANc.
} 
Las colonias y la península tuvieron, durante los años de funcionamiento del sistema de patentes ultramarino (1833-1898), diferentes organismos de registro y publicidad de las patentes concedidas (Fernández, 2008, pp. 113-119; Fernández de Pinedo, Pretel y Sáiz, 2010; Marqués, 2006, pp. 98, 224; Pretel, 2018). Esto significó la coexistencia de múltiples registros, sin comunicación administrativa fluida acerca de las patentes concedidas en una y otra institución, a pesar de que la legislación establecía que las patentes de ultramar debían ser publicadas en los órganos de la España metropolitana. Esta práctica hace muy difícil valorar la evolución, en el largo plazo, del número de solicitudes de patentes. Debido al procedimiento poco sistemático de concesión, así como a la fragmentación y falta de consistencia de los registros de patentes coloniales, el estudio cuantitativo de los datos de patentes coloniales es problemático ${ }^{26}$ Para este propósito, y sólo para el caso cubano, existen dos fuentes complementarias: en primer lugar, las memorias e informes elaborados por las elites hacendadas, como Memorias de la Sociedad Económica de La Habana, y en segundo lugar, los expedientes de tramitación de privilegios de invención custodiados en el Archivo Nacional de Cuba (en adelante ANC). El problema de la documentación custodiada en el ANC es que carece de un libro de registro estandarizado para todos los años y recoge además decenas de expedientes de solicitudes de apoyo público para el desarrollo de avances técnicos y agrícolas que no pueden ser considerados como solicitudes de patentes en sentido estricto. Entre la documentación de privilegios del ANC se encuentran también solicitudes de otras clases de monopolios comerciales e industriales, así como distintos tipos de ayudas.

Entre 1826 y 1898 se tramitaron en Cuba alrededor de 2600 solicitudes de privilegios de invención e introducción 27 Las solicitudes de protección se concentraron en invenciones relacionadas con la producción de azúcar, materiales de construcción, combustibles, transportes y maquinaria, pero también encontramos mejoras en diversos procedimientos organizativos. Asimismo, entre 1820 y 1898, se realizaron 575 solicitudes de privilegios de invención en los registros de la España metropolitana para residentes en Cuba, Filipinas y Puerto Rico (499 para Cuba, 61 para Puerto Rico y quince para Filipinas; la gran mayoría, 455 solicitudes, fue cursada entre 1880 y 1898). Decenas de estos privilegios fueron extendidos a las colonias por medio de trámite administrativo ante el Ministerio de Ultramar ${ }^{28}$ Por desgracia no hemos podido consultar hasta la fecha la documentación sistemática de registro de patentes para los casos de Puerto Rico y Filipinas, si bien disponemos de documentación indirecta y algunas, aunque escasas, referencias en fuentes secundarias (Cabrera-Salcedo, 2007, 2010).

Para el caso cubano, el periodo con mayor cantidad de solicitudes será el decenio de 1850 , con casi 830 solicitudes, que coinciden con la transformación tecnológica del sector azucarero de la isla. En el decenio de 1860 las solicitudes se reducirán a poco más de 500, y en el de 1870 serán apenas 130. La impresionante caída en la cantidad de solicitudes registradas en Cuba a partir de 1860 parece responder a cuestiones sociopolíticas y a la transición de las autoridades coloniales

\footnotetext{
${ }^{26}$ Existen incipientes estudios cliométricos de las patentes en América Latina, véase Beatty, Pineda y Sáiz (2017).

${ }^{27}$ Véanse las estimaciones de Sáiz y Fernández de Pinedo (2014) y Macle (2013).

${ }^{28}$ Ultramar, Ministerio de Ultramar Remite Patentes de Invención, núms. 127, 155, 156, 131, años 1888, 1889 y 1891-1893, y Convalidación de Patentes Dadas en la Península, núms. 178, 180, 182, 184, años 1893-1896, en AHN.
} 
hacia un modelo de gestión de patentes menos autónomo ${ }^{29}$ En el periodo de 1830 a 1860, las solicitudes de patentes en Cuba correspondían tanto a inventos extranjeros como a domésticos. Podría hablarse incluso de un predominio de invenciones criollas, resultado de la colaboración transnacional de distintos actores (Edgerton, 2007). Se disuelve así la distinción entre invenciones extranjeras y locales, y la plantación se revela como el espacio de desarrollo tecnológico.

Entre los solicitantes de patentes en el sistema cubano encontramos al estadunidense Alfred Cruger (ingeniero jefe de la línea de ferrocarril de La Habana a Güines), la casa comercial Drake Hermanos, la empresa Bell Telephone, el químico José Luis Casaseca, el fotógrafo profesional Esteban Mestre Aulet y los hacendados Juan Poey y Wanceslao de Villaurrutia. La gran mayoría de estas solicitudes de patente por parte de extranjeros era intermediada por residentes en $\mathrm{Cu}$ ba. Entre estos intermediarios destacan los hacendados y maquinistas que no sólo tramitaban las solicitudes extranjeras, sino adaptaban las nuevas tecnologías de producción de azúcar a las condiciones tropicales, como el clima y la topografía. Por ejemplo, el ingeniero francés Pierre Theodore Vaurigaud, profesor de la Escuela de Maquinaria de La Habana, intermedió en 1851 para obtener una patente como representante de Enrique Oliveiro Robiuson por una máquina de vapor para la producción de azúcar 30

Entre los solicitantes de patentes en el subsistema cubano encontramos también a numerosos maquinistas e ingenieros extranjeros, entre ellos Fernando Klever, Ezra Dod, Hiran Havens, Charles Edmonstone, Elisha Fitzgerald, Michael Glynn, Edward Beanes y James Ross. Por su superior seguridad, garantía jurídica y posibilidades de obtener ganancias económicas, estos maquinistas residentes en Cuba registraron también sus invenciones, concebidas en las plantaciones de las Antillas españolas, en oficinas de patentes del Reino Unido, Francia y, sobre todo, Estados Unidos (Curry-Machado, 2011). Por ejemplo, el ingeniero inglés Edward Beanes, que tenía una experiencia de dos decenios trabajando en plantaciones cubanas, obtuvo en 1865 una patente en Estados Unidos por mejoras en el refinado de azúcar mediante la neutralización de los ácidos del jugo de la caña, invento que también patentó en Cuba y Reino Unido 31

También se encuentran solicitudes de privilegios de hacendados puertorriqueños en Cuba. Por ejemplo, en 1868 Carlos Federico Schomburg, vecino de Puerto Rico, solicitó, a través de su representante en Cuba, José Peligero de Lama, dos privilegios, uno para un nuevo sistema de montura de pailas para elevar azúcar y un segundo para un sistema de riego por medio de pozos tubulares en combinación con bombas; ambos le fueron concedidos ${ }^{32}$ Otro puertorriqueño,

\footnotetext{
${ }^{29}$ Esta fuerte caída en la cantidad de solicitudes registradas en Cuba puede también deberse a una inconsistencia en la documentación histórica. En todos los sistemas de patentes, tanto estatales como coloniales, se encuentra un fuerte aumento de las solicitudes de patentes a partir del decenio de 1870, que se explica por la globalización económica de aquellos años y los acuerdos que eliminaron barreras a la transnacionalización de las patentes. $\mathrm{Al}$ respecto de esto último véase Inkster (2003 y 2009).

${ }^{30}$ Gaceta de La Habana (1 de enero de 1851), p. 1.

${ }^{31}$ Scientific American (23 de agosto de 1862), 1007(8), (25 de marzo de 1865), 1012(13) y The London Gazette (13 de enero de 1863).

${ }^{32}$ Gobierno General, leg. 441, exp. 21319, ANC.
} 
llamado Juan Ramos, patentó distintos procedimientos para la depuración y clarificación de la caña de azúcar en Puerto Rico, Cuba, España y Estados Unidos ${ }^{33}$ Ramos vendió algunos de estos derechos de patentes a emprendedores cubanos y estadunidenses. ${ }^{34}$

Los inventores franceses Charles Derosne y Jean Francois Cail, y sus sucesivas empresas de producción de maquinaria, estuvieron entre los más activos en el sistema cubano de patentes; en 1842 solicitaron privilegio de invención por un moderno tren de evaporación al vacío de azúcar en el que adaptaban a la caña de azúcar los adelantos en la elaboración del azúcar de remolacha Las corporaciones de la isla reconocieron el inmejorable adelanto que suponía esta instalación; sin embargo, dictaminaron no acceder a la concesión de patente, después de recabar tres informes, y en su lugar otorgarle un premio por su invención. La razón esgrimida por la Junta de Fomento fue que ese invento ya estaba introducido en Cuba y que la corporación había facilitado caudales para su transferencia. El informe de la Real Sociedad Económica de La Habana añadió que Dersone y Cail no eran "los inventores de la base principal del aparato" y que la concesión del monopolio resultaría en "un prejuicio al comercio y particularmente a los hacendados". De manera similar, a esta misma empresa se le denegó, en 1845, otro privilegio de introducción por un nuevo método de purga y cristalización del azúcar. El dictamen de la comisión, formada a tal efecto por la Real Junta, justificó en esta ocasión el rechazo en el elevado grado de adelanto tecnológico en que se encontraba la industria azucarera cubana ${ }^{36}$ La Junta de Fomento sí concedió a esta empresa francesa otras solicitudes de protección, como por ejemplo, en 1850, para una máquina que elaboraba azúcar sin el empleo de carbón animal 37

\section{CONVERGENCIA INSTITUCIONAL Y REFORMA DE LOS SISTEMAS COLONIALES}

En el último tercio del siglo xIx asistimos a una gradual transformación de los sistemas coloniales de patentes. En un contexto de creciente globalización tecnológica, la protección de la propiedad industrial limitada a los territorios nacionales fue señalada como inadecuada por gobiernos, inventores, empresas e intermediaros. La conveniencia de uniformidad legislativa entre los distintos sistemas de patentes, asimismo, empezó a ser demanda internacional habitual, incluida una presión por homogeneizar las legislaciones coloniales. Los economistas librecambistas, que tan fuertemente criticaron la protección de patentes durante los decenios centrales del siglo xix, perdían influencia (Machlup y Penrose, 1950; May y Sell, 2006).

\footnotetext{
${ }^{33}$ Privilegio de ultramar núm. 85 (11 de febrero de 1851), AHOEPM. US Patent núm. 9087 (29 de junio de 1852).

${ }^{34}$ Un caso singular es la cesión de derechos sobre una máquina de moler caña de azúcar que Juan Ramos acordó con Julio Leneven y José Coste a cambio de que los titulares de la patente establecieran un precio máximo de venta de este trapiche en Cuba de 425 pesos, de los cuáles 25 se cederían a favor de la casa de beneficencia de La Habana. Privilegio de ultramar núm. 50 (22 de mayo de 1841), АнОЕРм.

${ }^{35}$ Gobierno Superior Civil, leg. 1476, exp. 58365, ANC.

${ }^{36}$ Gobierno General, leg. 333, exp. 15986, ANC.

${ }^{37}$ Gobierno Superior Civil, leg. 1478, exp. 58514, ANc. No sólo encontramos denegación de privilegios en ramos agrícolas; por ejemplo, en 1844 la Junta de Fomento denegó la concesión de un privilegio de introducción a Juan Sparron para proteger un metal de composición aplicable a toda clase de máquinas. El dictamen señaló que no se daban las condiciones legales para la concesión por haberse utilizado el invento en varias reparaciones en el taller del depósito de La Habana para ferrocarriles que van a Güines. Memorias de la Sociedad Económica, Imprenta del Gobierno y Capitanía General (La Habana, 1843), t. XvII, pp. 388-389.
} 
A partir del decenio de 1880 se firmaron diversos tratados supranacionales que regularon internacionalmente los derechos de patentes de invención. Entre ellos destaca el Convenio Internacional para la Protección de la Propiedad Industrial suscrito en París en 1883 que, con revisiones posteriores, sigue vigente hasta nuestros días (Penrose, 1951; Plasseraud y Savignon, 1983; Ricketson, 2015). Entre los estados contratantes 38 se encontraban potencias coloniales como España, Francia, Bélgica y Portugal. También estuvieron representados países de América Latina como Brasil, El Salvador y Guatemala. Otros centros imperiales se incorporarán en poco tiempo, como Reino Unido en 1884 y Estados Unidos en 1887. El convenio de 1883 -uno de los primeros tratados multilaterales de la historia- consagró la doctrina de derecho natural de la invención, el principio de tratamiento nacional y el derecho de prioridad. Su principal logro fue la constitución, en 1884, de la Unión para la Protección de la Propiedad Industrial y el establecimiento de una Oficina de la Unión Internacional con sede en Berna 39

En el congreso de 1883 se abordó la problemática de los sistemas de patentes coloniales, si bien no se acordó regulación al respecto. En el largo plazo, la Convención de París sí tendrá efectos notables en espacios coloniales (Ricketson, 2015). Durante los decenios de 1880 y 1890, las conferencias de revisión que seguirán al Convenio de París sí incluirán en los acuerdos referencias a la regulación colonial, con escasos efectos jurídicos, por la oposición de España y Estados Unidos (Gálvez-Behar, 2016). Así, el reglamento para la ejecución del convenio, aprobado en Roma en 188640 disponía que fuera prerrogativa de las metrópolis indicar cuáles de sus "territorios, colonias o posesiones" formarían parte de la Unión. En esa ocasión, el representante español, Mariano de Larra, por entonces director del Boletín Oficial de la Propiedad Industrial, declaró a la asamblea, siguiendo las instrucciones recibidas del gobierno español, que las islas de Cuba, Puerto Rico y Filipinas debían ser consideradas partícipes de la Unión por la adhesión de la metrópoli ${ }^{41}$ Otras colonias, protectorados y territorios dependientes también se adhirieron en los años siguientes a la Convención de París, por ejemplo Siria, Túnez y Argelia, por parte de Francia; Azores y Madeira, por parte de Portugal, o Surinam y Curasao, en el caso holandés. En la conferencia de Washington de 1911 se añadirá explícitamente al Convenio de París la posibilidad de solicitud directa de adhesión de colonias y territorios dependientes.

Durante los mismos años, al final del decenio de 1880, y como respuesta a la Unión de París, se creará un sistema interamericano de patentes vinculado con la celebración de las Conferencias Panamericanas (Ladas, 1975) ${ }^{42}$ en la primera, en Washington entre octubre de 1889 y abril de 1890, Estados Unidos y varias repúblicas latinoamericanas, como México y Brasil, discutieron, entre otros temas, la adopción de acuerdos en materia de patentes o privilegios de invención. En la conferencia se recomendó la adhesión al tratado sobre patentes que varias naciones americanas habían firmado en el Congreso Sudamericano de Derecho Internacional Privado, celebrado en Montevideo un año antes. En la primera Conferencia Panamericana no estuvieron representados todos los países hispanoamericanos, faltaron Santo Domingo, Cuba y Puerto Rico; el primero de-

\footnotetext{
${ }^{38}$ El Convenio de París, desde la revisión incluida en 1934, en Londres, hace referencia a los países que subscriben el convenio y no a los Estados contratantes, como ocurría hasta entonces, con el objetivo de englobar también a las colonias, los protectorados y otros tipos de dominios.

${ }^{39}$ Paris Convention for the Protection of Industrial Property (1883). World Intellectual Property Organization, Administered Treaties [wIPo]. Disponible en http://www.wipo.int/treaties/en/text.jsp?file_id=288514

${ }^{40}$ Reglamento para la ejecución del convenio firmado en París en 1883. Disposición aclaratoria núm. 3.

${ }^{41}$ Boletín Oficial de la Propiedad Industrial (1 de diciembre de 1886), 1(7).

${ }^{42}$ Véase también el New York Times (4 de marzo de 1890), p. 3.
} 
negó la invitación por sus disputas territoriales con Estados Unidos y las otras dos islas del Caribe no pudieron asistir por ser aún colonias de España. En 1902, en la segunda Conferencia Panamericana, celebrada en México, se firmó un tratado sobre patentes de invención, dibujos industriales y marcas de comercio de fábrica, suscrito, entre otros países, por Argentina, Bolivia, Chile, México, Perú y Uruguay. Estados Unidos y Cuba, ya independizada de España, también se adhieren al tratado 43

A pesar de los diferentes acuerdos internacionales, hasta 1898 continuará funcionando un sistema de patentes colonial en las islas de Cuba, Puerto Rico y Filipinas, que habían reafirmado su relativa autonomía en la materia con la legislación especial colonial de propiedad industrial de $1880{ }^{44}$ Los gobernadores generales de las colonias conservaron, en los dos últimos decenios del siglo XIX, la prerrogativa de conceder patentes de invención. A diferencia de la legislación de 1833, la concesión de patentes en la metrópoli pasó a tener efectos legales en todos los dominios españoles, sin necesidad, como hasta entonces, de abonar cuatro veces las tasas de registro. Toda patente metropolitana se consideraba concedida no sólo para la península, sino para las provincias de ultramar. Las tasas de registro, como también ocurrió en la península con la ley de 1878, pasarán a ser de tipo progresivo, lo que supuso un fuerte aumento, entre 1880 y 1898, en la solicitud de patentes en los registros de la España metropolitana por parte de residentes en las colonias. El título metropolitano protegía en todos los dominios, si bien era necesaria una solicitud específica y un testimonio legalizado ante el Ministerio de Ultramar para que los derechos de patentes fueran extendidos a las colonias. Los inventores podían también legalizar sus patentes directamente ante los gobernadores generales de cada provincia de ultramar, a quienes les correspondía llevar un registro general de patentes y publicar la información de las concesiones en la gaceta oficial de cada provincia. Parece que esta legislación especial se siguió prestando a abusos e inseguridad jurídica, como denunció el ingeniero industrial Gumersindo Vicuña, profesor de física matemática en la Universidad Central de Madrid y antiguo director general de Agricultura, Industria y Comercio (Vicuña, 1882, p. 144).

De la misma manera, cualquier patente concedida en ultramar podía ser extendida a los otros dominios españoles, incluida la península, por medio de instancia al gobernador general de la respectiva colonia, sin costo adicional alguno. Las dificultades que encontraban los solicitantes extranjeros para satisfacer los complejos requerimientos administrativos de la legislación colonial, como la certificación de la puesta en práctica y la redacción de las especificaciones, llevaron a la proliferación de agentes intermediarios en la solicitud de patentes. Tres agencias dominaron la lucrativa actividad de intermediación de patentes en las colonias españolas: Elzaburu (fundada por el abogado puertorriqueño Julio Vizcarrondo); Clarke, Modet \& Co. y el Centro Auxiliar de la Industria. Esta situación ya había sido denunciada en 1877 en uno de los editoriales de la revista mecánica madrileña La Crónica de la Industria: "si desea que, como español, su invento se proteja en toda España, entonces es necesario que atraviese los mares, que nombre agentes en Cuba, Puerto Rico y Filipinas, obtenga tres nuevos privilegios y apronte casi una fortuna" ${ }^{45}$

\footnotetext{
${ }^{43}$ Tratado sobre patentes de invención, dibujos y modelos industriales, y marcas de comercio y de fábrica, Segunda Conferencia Internacional Americana, México, del 22 de octubre de 1901 al 31 de enero de 1902, Conferencias Internacionales Americanas 1889-1936, Biblioteca Digital Daniel Cosío Villegas (El Colegio de México).

${ }^{44}$ Real decreto del 14 de mayo de 1880 que dictó reglas para la aplicación de la ley del 30 de julio de 1878 sobre patentes de invención a las provincias de ultramar.

${ }^{45}$ Crónica de la Industria (15 de octubre de 1887), núm. 68, pp. 293-294.
} 
En definitiva, a pesar de la nueva reglamentación de 1880, siguieron existiendo dos sistemas de patentes distintos: uno, con lo legislado para la península y en el que las concesiones eran reconocidas en todos los dominios españoles; y otro, colonial, en el que se solicitaban los privilegios que en principio sólo tenían efecto en ultramar (García-Garófalo, 1890). La España ultramarina tuvo, asimismo, una legislación específica sobre marcas, dibujos y modelos industriales, gracias a la ley de 1884, proyecto presentado por iniciativa de Manuel Aguirre de Tejada, ministro de Ultramar, inmediatamente después de los acuerdos de la Convención de París ${ }^{46}$ La existencia de una ley específica de marcas colonial se justificó por la necesidad de una protección efectiva de la industria del tabaco en las dos Antillas. Esta situación fue denunciada por el prestigioso abogado de patentes José Pella y Forgás, autor en 1892 de Las Patentes de Invención y los Derechos de Inventor, uno de los tratados sobre patentes de invención más extensos y destacados de la época: "No se explica sino por la desidia que caracteriza a los gobiernos españoles la anomalía de poseer legislación de modelos industriales para ultramar y no tenerla para España” (Pella y Forgás, 1892). En realidad, tampoco los hacendados cubanos parecían contentos con la paulatina formalización del sistema colonial de propiedad industrial. Francisco Zayas, director de la Revista de Agricultura, órgano oficial del Círculo de Hacendados de la Isla de Cuba, señalaba en 1880: "La máquina o máquinas y aparatos que han de hacer la extracción y concentración de ese rico jugo, no es ningún invento privilegiado por una patente, que sólo pueden emplear uno o unos pocos constituidos en sociedad" 47

En el último tercio del siglo XIX se redujeron drásticamente las solicitudes de patentes de invención en los registros cubanos. Dicho esto, se aprecia al mismo tiempo una creciente actividad en el sistema de patentes colonial de los inventores y las empresas estadunidenses. Por ejemplo, la división neoyorquina de la empresa de maquinaria Babcok \& Wilcox solicitó en 1885 privilegio por diez años para una mejora en la construcción de calderas de vapor. El dictamen de la Real Sociedad Económica de Amigos del País de La Habana fue favorable. En este caso el ingeniero Alberto Verastegui, representante de la empresa en la isla, solicitó, y se le concedió, extensión del plazo de puesta en práctica de la invención, por ser este "sumamente corto cuando se trata de una industria que ha de explotarse en grande escala y que requiere el auxilio de costosas máquinas, plantillas y modelos para su fabricación" 48 Frederick Cook, ingeniero de la compañía Babcock Wilcox, también obtuvo un privilegio en La Habana, pocos años más tarde, en 1889, por un aparato automático completo para quemar bagazo verde en combinación con una batería de calderas seccionales. En esta ocasión la duración de la protección fue por quince años 49

Buena muestra de la creciente influencia estadunidense son los artículos aparecidos en la revista La América Científica e Industrial, publicada desde 1880 en Nueva York por la agencia de patentes Munn \& Company. Esta revista de patentes se publicaba acompañada por la Scientific American Export Edition y estaba especialmente dirigida a los países latinoamericanos de habla española, donde la agencia de patentes Munn \& Co. y los inventores americanos a los que representaba solían extender derechos de patentes. Las colonias españolas de Cuba y Puerto Rico fueron objeto de

\footnotetext{
${ }^{46}$ Real decreto del 21 de agosto de 1884. CLE (t. CXxxvi). La ley especial de marcas industriales para las provincias de ultramar buscaba de manera explícita la protección de la industria del tabaco en las dos Antillas españolas, ante la inseguridad que enfrentaban los productores. Véase también Marcas, Modelos y Dibujos Industriales en Ultramar, Industria e Invenciones (6 de agosto de 1884), pp. 88-89.

${ }^{47}$ Revista de Agricultura (31 de octubre de 1880), núm. 10, p. 310.

${ }^{48}$ Gobierno General, leg. 455, exp. 22246, ANC.

${ }^{49}$ Gobierno General, leg. 458, exp. 22481, ANC.
} 
numerosos artículos de las revistas publicadas por Munn \& Co., tanto en su edición en inglés como en español. Muchos de estos textos destacaban las oportunidades que presentaban la transición al central azucarero en la agroindustria caribeña para los inventores, ingenieros y fabricantes de maquinaria de Estados Unidos.

Las empresas de Thomas Alva Edison fueron especialmente activas en entornos coloniales, como India, Sudáfrica, Ceilán y Australia. En cuanto a las colonias españolas, en el decenio de 1880 se establecieron varias compañías en Nueva York para controlar, publicitar y licenciar tecnologías patentadas en Cuba, Puerto Rico y “otras colonias españolas”: la Electric Light Company of Cuba and Porto Rico, la Edison Electric Light Company of Havana, la Edison Spanish and Colonial Electric Light Company y La Havana Electric Light Company (Hausman, Hertner y Wilkins, 2008, pp. 77-78) ${ }^{50}$ Estas empresas se constituyeron principalmente para controlar patentes y comercializar tecnología, como plantas de iluminación eléctrica para centrales azucareras y centros urbanos. Thomas A. Edison cedió a estas compañías coloniales varias patentes que se le habían otorgado con anterioridad en España. La Edison Spanish Colonial Light Company incluso tuvo desde 1882 hasta 1884 una planta de exhibición en La Habana, con el estadunidense Edward Beardsley como ingeniero jefe. De acuerdo con el ingeniero eléctrico Thomas C. Martin y el abogado de patentes Frank L. Dyer, a estas compañías se les otorgaron doce patentes en Cuba (Dyer y Martin, 1910). La Edison Spanish Colonial Light Company también obtuvo en Madrid varias patentes en el decenio de 1880 sobre distribución eléctrica y lámparas incandescentes. 51

Con la independencia de Cuba, Filipinas y Puerto Rico en 1898, se asiste a una reconfiguración de los derechos de propiedad industrial en estos territorios. A partir de 1898 Estados Unidos impuso un nuevo sistema de patentes en las colonias españolas. En el Tratado de París de 1898 entre España y Estados Unidos se discutieron, entre otras cosas, medidas legislativas transitorias en materia de derechos de patentes, adoptándose algunas provisiones (Bellido, Xalabarder y Casas, 2011). A partir de noviembre de 1899 todas las patentes en vigor en Estados Unidos pasaron a ser reconocidas en las colonias españolas ${ }^{52}$ Por su parte, en 1899, España estableció un periodo de tres meses para que los titulares de patentes en Cuba, que no pudieron hacerlo durante la guerra, se pusieran al día en el pago de anualidades ${ }^{53}$ Un año después, en mayo de 1900, por orden militar, se estableció que todos los titulares de patentes registradas en Cuba que quisieran amparo de Estados Unidos debían revalidar sus certificados acreditativos de registro ante las nuevas autoridades de la isla $\sqrt{54}$ Finalmente, en 1904, Cuba se adhirió al Convenio de París para la Protección de la Propiedad Industrial, además de haber ratificado el tratado sobre patentes de invención acordado en la Segunda Conferencia Internacional Americana en enero de 1902 en México.

\section{Conclusiones}

El objetivo de este texto ha sido estudiar la evolución de los sistemas coloniales de patentes durante el siglo XIx, tomando como ejemplo el caso español. La existencia de una institución de patentes colonial no fue una excepción española. La regulación formal de los derechos de patentes

\footnotetext{
${ }^{50}$ Edison Spanish Colonial Light Co. (1882) y Thomas Alva Edison Papers [XX19KA; TAEM 0:00], 5 de septiembre de 1881.

${ }^{51}$ Patentes núms. 1657 y 2023, AHOEPM, у TAEP [HM820157; TAEM 86:452], 2 de septiembre de 1882.

${ }^{52}$ Circular del 12 de noviembre de 1899.

${ }^{53}$ Real decreto del 17 de febrero de 1899.

${ }^{54}$ Orden militar, núm. 216 (26 de mayo de 1900).
} 
en las colonias inglesas, francesas y españolas fue impuesta por las respectivas metrópolis. Ahora bien, el funcionamiento de dichas instituciones muestra que esta no es tan sólo una historia de intervención imperial, sino de descentralización con distintos grados de coordinación con las metrópolis. En muchos de estos dominios la protección de patentes no era deseable o necesaria. Tampoco parece que hubiera al respecto una estrategia coherente de los centros imperiales. Existía poca preocupación de las potencias coloniales por homogeneizar estos divergentes sistemas de patentes, por lo que se mantuvieron su debilidad legal e imperfección institucional.

Durante el siglo XIX compitieron distintos modelos de regulación del derecho de propiedad industrial. Las legislaciones coloniales respondieron a las necesidades de las economías coloniales, antes que a una lógica de índole filosófico o a cuestiones morales. En América Latina se toma como modelo preferido el sistema francés. Respecto de los sistemas coloniales, se encuentra una práctica del derecho de patentes distinta a la concepción habitual hoy en día. El sistema de patentes colonial español entre 1830 y el decenio de 1860 tenía tres elementos definitorios; en primer lugar, se caracterizaba por una concesión discrecional, con decisiones ad-hoc y respaldada por una legislación confusa, ambigua y excepcional. El dualismo de la legislación permitió a las elites coloniales preservar la autoridad de conceder privilegios monopolistas. Los gobernadores generales tenían reservada la prerrogativa de conceder privilegios de invención en función de las necesidades económicas de sus territorios. Distintas corporaciones coloniales actuaban como consultores. Se empleaba un incentivo utilitario, de corte neomercantilista. También fueron utilitarios los criterios de patentabilidad, que en la práctica restringían la concesión de patentes en sectores económicos estratégicos o avanzados.

Esta imperfección institucional ofrecía claras ventajas. Las invenciones extranjeras podían ser introducidas en las economías coloniales sin los costos adicionales que supondría un sistema de patentes garantista. La autoridad colonial administró estos sistemas de manera pragmática, guiada por los imperativos de sus economías. Había una concepción de las patentes como privilegio exclusivo para emprender una actividad económica, antes que un derecho natural del inventor. Las patentes eran vistas en la práctica como privilegios y no como derechos o méritos. El contrato entre el solicitante y la administración colonial se centraba fundamentalmente en la puesta en práctica de la nueva tecnología en ese territorio. El objetivo era promover la aplicabilidad económica del invento en la colonia, no proteger o incentivar al autor del invento; es decir, lo definitorio eran los intereses económicos de las elites coloniales.

En segundo lugar, se trataba de un sistema con una administración no profesionalizada. Las corporaciones coloniales conformadas por las elites económicas y políticas locales actuaban de oficinas de registro, evaluación y publicidad de las patentes. No había un procedimiento administrativo estandarizado de concesión. La legislación establecía que el titular de una patente podía demandar judicialmente al usurpador de su propiedad, aunque no parece que la jurisprudencia ni los tribunales fueran garantistas. En los dictámenes de concesión se valoraban cuestiones como el precio de los bienes, el costo de la maquinaria, la política comercial o la posible competencia de nuevos productores. Tampoco había un cuerpo burocrático especializado en la concesión de patentes, como sí se conformaría (aunque muy reducido, falto de recursos y menguante) en la España metropolitana durante el siglo xIx. Aunque es un aspecto difícil de analizar de manera sistemática, parece claro que los derechos de propiedad del invento eran débiles y difíciles de hacer cumplir. La naturaleza incremental de muchas de las innovaciones introducidas en las economías coloniales dificultaba la detección de incumplimientos en los derechos de patentes, siendo los derechos de 
propiedad del invento de poca utilidad para sus titulares ante la incertidumbre legal. Las patentes coloniales fueron una limitada fuente de extracción de rentas, ante el prácticamente inexistente mercado de patentes en las economías coloniales.

En tercer lugar, el tipo de protección que ofrecían estas instituciones coloniales también era variado, en muchas ocasiones mediante incentivos alternativos a las patentes. Las corporaciones coloniales, en su objetivo de estimular la innovación, promovieron premios, subsidios, comisiones de estudio, viajes, traducción de textos y otros monopolios de explotación. Estos instrumentos entraban frecuentemente en conflicto con la concesión de patentes. Así, las corporaciones coloniales tejieron una infraestructura social para el intercambio de información práctica, cuyo objetivo era evitar el secretismo tecnológico. Estas instituciones eran nodos en las redes de intercambio de conocimiento tecnológico en el Atlántico, redes que no sólo intercambiaron técnicas, sino también circularon derechos, expertos, textos e ideas. Al menos en el caso de Cuba, en el periodo de 1820 a 1860, esta estrategia de promoción de la innovación permitió la circulación de nuevos inventos y procedimientos agroindustriales, lo que también fomentó la experimentación y las mejoras de tipo incremental en las plantaciones, basadas en la experiencia práctica. Ahora bien, este sistema colonial de patentes se institucionalizó de manera divergente, lo que pone de manifiesto que arreglos institucionales alternativos a las patentes podrían haber sido tanto o más efectivos.

Las dinámicas políticas internacionales fueron un determinante en la evolución del sistema de patentes en las colonias españolas. La presión internacional por estandarizar y armonizar la legislación de patentes inició un lento proceso de transformación de dichos sistemas coloniales de patentes durante los dos últimos decenios del siglo xix. En 1898, Cuba, Filipinas y Puerto Rico pasaron a ser nominalmente estados soberanos, si bien sujetos a la intervención de Estados Unidos. En materia de propiedad industrial, a partir de ese momento Estados Unidos introdujo medidas legislativas que garantizaban un reconocimiento recíproco de las patentes concedidas. Los efectos del Convenio de París de 1883 y de las Conferencias Panamericanas sólo se harán sentir en las antiguas colonias españolas ya entrado el siglo xx.

\section{LISTA DE REFERENCIAS}

Alcover, J. (1884). Situación agrícola e industrial en la isla de Cuba. La Gaceta Industrial, 14.

Anales de las Reales Junta de Fomento y Sociedad Económica (1849). Anales de las Reales Junta de Fomento y Real Sociedad Económica. La Habana: Imprenta del Gobierno y Capitanía General por S. M.

Arapostathis, S. y Gooday, G. (2013). Patently contestable: electrical technologies and inventor identities on trial in Britain. Cambridge: MIT Press.

Beatty, E. (2001). Institutions and investment: the political basis of industrialization in Mexico before 1911. Stanford: Stanford University Press.

Beatty, E., Pineda, Y. y Sáiz, P. (2017). Technology in Latin America's Past and Present: New Evidence from the Patent Records. Latin American Research Review, 52(1), 138-149. DOI: 10.25222/larr.46

Bellido, J., Xalabarder, R. y Casas, R. Commentary on: Treaty of Peace between the United States and Spain (1898). En L. Bently y M. Kretschmer (eds.), Primary sources on copyright, 14501900. Recuperado de www.copyrighthistory.org 
Bently, L. (2011). The "Extraordinary Multiplicity" of Intellectual Property Laws in the British Colonies in the Nineteenth Century. Theoretical Inquiries in Law, 12(1), 161-200. DOI: 10.2202/1565-3404.1266

Bracha, O. (2016). Owning ideas: the intellectual origins of American intellectual property, 1790-1909. Cambridge: Cambridge University Press.

Cabrera-Salcedo, L. (2007). Inventos para el azúcar: historia tecnológica puertorriqueña, siglo XIX. San Juan: Instituto de Cultura Puertorriqueña.

Cabrera-Salcedo, L. (2010). De los bueyes al vapor: caminos de la tecnología del azúcar en Puerto Rico y el Caribe. San Juan: Universidad de Puerto Rico.

Chang, H. (2001). Intellectual Property Rights and Economic Development: Historical lessons and emerging issues. Journal of Human Development, 2(2), 287-309. DOI: 10.1080/146498801 20067293

Chang, H. (2003). Globalization, economic development, and the role of the state. Londres: Zed Books.

Curry-Machado, J. (2011). Cuban sugar industry: transnational networks and engineering migrants in mid-ninetheenth century Cuba. Nueva York: Palgrave Macmillan. DOI: 10.1057/9780230118 881

Dyer, F. L. y Martin, T. C. (1910). Edison: his life and inventions (Vol. 2). Nueva York: Harper \& Bros.

Edgerton, D. E. H. (1999). From innovation to use: Ten eclectic theses on the historiography of technology. History and Technology, 16(2), 111-136. DOI: 10.1080/07341519908581961

Edgerton, D. E. H. (2007). Creole technologies and global histories: rethinking how things travel in space and time. Journal of History of Science and Technology, 1(1), 75-112.

Edison Spanish Colonial Light Co. (1882). La luz Edison/Luz eléctrica incandescente. Nueva York: Imprenta y Librería de N. Ponce de León.

Escobar, B. (2004). The doctrines and the making of an early patent system in the developing world: the Chilean case. 1840s-1910s (Working Paper No. 58). Chile: Universidad Diego Portales. Recuperado de https://ideas.repec.org/p/ptl/wpaper/58.html

España. (1820). Diario de las actas y discusiones de las Cortes: legislatura de los años de 1820 y 1821. Madrid: Imprenta de las Cortes, por don García y Campoy.

Fernández, L. (2008). Espacio de poder, ciencia y agricultura en Cuba: el Círculo de Hacendados, 18781917. Madrid: Consejo Superior de Investigaciones Científicas.

Fernández de Pinedo, N., Pretel, D. y Sáiz, P. (2010). Patents, sugar technology and sub-imperial Institutions in Nineteenth-Century Cuba. En I. Inkster (ed.), History of technology (Vol. 30: European technologies in Spanish History, pp. 47-62). Nueva York: Continuum Publishing Corporation.

Fradera, J. M. (1999). Filipinas, la colonia más peculiar: la hacienda pública en la definición de la política colonial, 1762-1868. Madrid: Consejo Superior de Investigaciones Científicas.

Fradera, J. M. (2008). L'esclavage et la logique constitutionnelle des empires. Annales. Histoire, Sciences Sociales, 63(3), 533-560. DOI: 10.1017/S0395264900023313

Gálvez-Behar, G. (2016). Les empires et leurs brevets. En L. Hilaire-Pérez y L. G. Zakharova (eds.), Les techniques et la globalisation au XXe siècle (pp. 281-296). Rennes: Presses Universitaires de Rennes. Recuperado de https://halshs.archives-ouvertes.fr/halshs-00839585v2

García-Garófalo, M. F. (1890). La propiedad intelectual e industrial, su legislación en la península y provincias ultramarinas. La Habana: La Propaganda Literaria. 
Gerschenkron, A. (1962). Economic Backwardness in historical perspective. Cambridge: Harvard University Press.

Griliches, Z. (1990). Patent Statistics as Economic Indicators: A Survey (No. w3301). Cambridge: National Bureau of Economic Research. DOI: 10.3386/w3301

Hausman, W. J., Hertner, P. y Wilkins, M. (2008). Global Electrification: Multinational Enterprise and International Finance in the History of Light and Power, 1878-2007. Cambridge: Cambridge University Press. DOI: 10.1017/CBO9780511512131

Inkster, I. (2003). Patents as Indicators of Technological Change and Innovation: An Historical Analysis of the Patent Data 1830-1914. Transactions of the Newcomen Society, 73(2), 179-208. DOI: $10.1179 /$ tns.2003.010

Inkster, I. (2009). Institutional patterns and outcomes circa 1421-2000. En D. Castle (ed.), The role of intellectual property rights in biotechnology innovation (pp. 413-436). Cheltenham: Edward Elgar.

Inkster, I. (2012). Highly Fraught with Good to Man: Patent Organisation, Agency and Useful and Reliable Knowledge in British Machinofacture circa 1780-1851 and beyond. En I. Inskster (ed.), History of technology (Vol. 31, pp. 115-144). Londres: Bloomsbury Publishing.

Knight, F. W. (1977). Origins of Wealth and the Sugar Revolution in Cuba, 1750-1850. The Hispanic American Historical Review, 57(2), 231. DOI: 10.2307/2513773

Knight, H. J. (2011). Confederate invention: the story of the Confederate States Patent Office and its inventors. Baton Rouge: Louisiana State University Press.

Ladas, S. P. (1975). Patents, trademarks, and related rights: national and international protection. Cambridge: Harvard University Press.

Machlup, F. y Penrose, E. (1950). The Patent Controversy in the Nineteenth Century. The Journal of Economic History, 10(01), 1-29. DOI: 10.1017/S0022050700055893

Macle, J. (2013). Los privilegios de invención existentes en el ANC. Inédito.

Marqués, M. A. (2006). Las industrias menores: empresarios y empresas en Cuba (1880-1920). La Habana: Ciencias Sociales.

Marrero, L. (1984). Cuba: economía y sociedad. Madrid: Playor.

May, C. y Sell, S. K. (2006). Intellectual property rights: a critical history. Boulder: Lynne Rienner Publishers.

Moreno, M. (1995). Cuba-España, España-Cuba: historia común. Barcelona: Crítica.

Muir, A. F. (1946). Patents and Copyrights in the Republic of Texas. The Journal of Southern History, 12(2), 204. DOI: $10.2307 / 2198150$

Nard, C. A. (2010). Legal forms and the common law of patents. Boston University Law Review, 50(1), 51-108.

North, D. C. (1990). Institutions, Institutional Change and Economic Performance. Cambridge: Cambridge University Press. DOI: 10.1017/CBO9780511808678

Ortega, J. G. (2014). Machines, modernity, and sugar: the Greater Caribbean in a global context, 1812-50. Journal of Global History, 9(1), 1-25. DOI: 10.1017/S1740022813000478

Ostrom, E. (2015). Comprender la diversidad institucional. (M. Moro Vallina, Trad.). México: Fondo de Cultura Económica/Universidad Autónoma Metropolitana.

Paris Convention for the Protection of Industrial Property (1883). WIPO-Administered Treaties: Paris Convention for the Protection of Industrial Property. Recuperado de https://www.wipo.in t/treaties/en/text.jsp?file_id=288514 
Patel, S. J. (1974). The patent system and the third world. World Development, 2(9), 3-14. DOI: 10.1016/0305-750X(74)90084-9

Pella y Forgas, J. (1892). Las patentes de invención y los derechos del inventor: tratado de utilidad práctica para inventores é industriales. Barcelona: Administración de Industria é Invenciones.

Penrose, E. T. (1951). The economics of the international patent system. Baltimore: Johns Hopkins Press.

Plasseraud, Y. y Savignon, F. (1983). Paris 1883: genèse du droit unioniste des brevets. París: Litec.

Pretel, D. (2017). La economía política del sistema español de patentes en perspectiva internacional (1826-1902). Investigaciones de Historia Económica, 13(3), 190-200. DOI:10.1016/j.ihe.20 17.01 .003

Pretel, D. (2018). Institutionalising Patents in Nineteenth-Century Spain. Londres: Palgrave-Macmillan. DOI: $10.1007 / 978-3-319-96298-6$

Pretel, D. y Fernández de Pinedo, N. (2015). Circuits of Knowledge: Foreign Technology and Transnational Expertise in Nineteenth-century Cuba. En A. B. Leonard y D. Pretel (eds.), The Caribbean and the Atlantic World Economy (pp. 263-289). Londres: Palgrave Macmillan. DOI: $10.1057 / 9781137432728 \_12$

Real Sociedad Económica (1843). Memorias de la Sociedad Económica. La Habana: Imprenta de la Capitanía General.

Real Sociedad Económica (1846). Memorias de la Real Sociedad Económica de la Habana. La Habana: Oficina del Gobierno y Capitanía General.

Ricketson, S. (2015). The Paris Convention for the Protection of Industrial Property: a commentary. Oxford: Oxford University Press.

Rood, D. (2017). The reinvention of Atlantic slavery: technology, labor, race, and capitalism in the greater Caribbean. Nueva York: Oxford University Press.

Sagar, R. (2007). Introduction of exclusive privileges. Patents in colonial India: why and for whose benefit? Intellectual Property Quarterly, 2, 164.

Sáiz, P. (2006). Transferencia Internacional de Tecnología hacia España a través del Sistema de Patentes (1759-1900). En M. Merger (ed.), Transferts de technologies en Méditerranée (pp. 2952). París: Presses de l'Université Paris-Sorbonne.

Sáiz, P. y Fernández de Pinedo, N. (dirs.) (2014). Base de datos de solicitudes de privilegios de invención. Cuba (1830-1898). Madrid: Universidad Autónoma de Madrid.

Sánchez, R. (1980). Historia de la tecnología y la invención en México: introducción a su estudio y documentos para los anales de la técnica. Mexico: Fomento Cultural Banamex.

Sánchez, J. (1997). Comienzos de la formación de la técnica minerometalúrgica colonial. En J. S. Gómez, G. Mira y R. Dobado (eds.), La savia del imperio: tres estudios de economía colonial (pp. 57-80). Salamanca: Universidad de Salamanca.

Schmidt-Nowara, C. (2004). "La España Ultramarina”: Colonialism and Nation-Building in Nine teenth-Century Spain. European History Quarterly, 34(2), 191-214. DOI: 10.1177/026569140 4042507

Sociedad Patriótica (1836). Memorias de la Sociedad Patriótica de La Habana. La Habana: Oficina del Gobierno y Capitanía General.

Sociedad Patriótica (1839). Memorias de la Sociedad Patriótica de La Habana. La Habana: Imprenta del Gobierno y Capitanía General por S. M.

Streb, J. (2016). The cliometric study of innovations. En C. Diebolt y M. Haupert (eds.), Handbook of cliometrics (pp. 447-468). Berlin-Heidelberg: Springer. 
Thompson, W. P. (1882). Handbook of patent law of all countries. Londres: Stevens \& Sons/D. Van Nostrand.

Todd, J. (1995). Colonial technology: science and the transfer of innovation to Australia. Cambridge: Cambridge University Press.

Trentmann, F. y Daunton, M. (2004). Worlds of political economy: knowledge, practices and contestation. En M. Daunton y F. Trentmann (eds.), Worlds of Political Economy: Knowledge and Power in the Nineteenth and Twentieth Centuries (pp. 1-23). Nueva York: Palgrave Macmillan.

Vicuña, G. (1882). Las patentes y marcas de Ultramar. La Semana Industrial, 15.

Woodcroft, B. (1969). Alphabetical index of patentees of inventions, 1617-1852. Londres: Evelyn, Adams \& MacKay.

Archivos

AHN Archivo Histórico Nacional, Madrid.

ANC Archivo Nacional de Cuba, La Habana.

Ahoepm Archivo de la Oficina Española de Patentes y Marcas, Madrid.

taep The Thomas A. Edison Papers, Rutgers University. 